\title{
A NOÇÃO HUSSERLIANA DE SUBJETIVIDADE TRANSCENDENTAL
}

\author{
Alberto Marcos Onate*
}

SÍNTESE - Baseado no cogito cartesiano, mas também o submetendo a importantes reformulacões, Husserl desenvolve o seu próprio conceito de subjetividade transcendental. Tais reformulações concernem, sobretudo, aos tópicos do tempo, da redução e da intersubjetividade. O presente artigo pretende apresentar e discutir como se vinculam tais temas, visando a contribuir na compreensão do estatuto do transcendental na fenomenologia husserliana.

PALAVRAS-CHAVE - Husserl. Subjetividade transcendental. Tempo.
ABSTRACT - Based on Cartesian cogito, but also submitting it to important reformations, Husserl develops his own concept of transcendental subjectivity. These reformations concern especially the topics of time, reduction and intersubjectivity. This article intends to present and discuss the link of these themes, aiming contribute to the comprehension of the status of transcendental in husserlian phenomenology.

KEY WORDS - Husserl. Transcendental subjectivity. Time.

No final do segundo parágrafo da obra Meditações Cartesianas, Edmund Husserl adverte em tom enfático: "É evidente que observaremos uma extrema prudência crítica, sempre prontos a transformar o antigo cartesianismo onde necessário. Deveremos também esclarecer e evitar certos erros sedutores de que nem Descartes nem seus sucessores souberam evitar a cilada". Tal circunspecção permitiria detectar duas grandes omissões cartesianas no tratamento do cogito: a primeira concernente à falta de exploração cabal do caráter metódico da dúvida, que impediu a abertura ao âmbito da epokhé; a segunda decorrente da negligência quanto ao caráter necessariamente intencional da consciência. Privada desses ajustes, a descoberta arquimediana do filósofo francês encontrava-se fadada a permanecer estéril. Descartes, influenciado pelo modus operandi e pelas conquistas das ciências matemáticas, teria transposto os métodos destas para a investigação filosófica, acabando por transformar o cogito em fundamento inconcusso, axioma que sustenta uma sofisticada cadeia dedutiva.

A redução fenomenológica, da maneira como Husserl a propõe, não se limita à passagem da atitude natural à atitude transcendental, mas implica, sobretudo,

* UNIOESTE (PR).

\begin{tabular}{|l|l|l|l|l|l|}
\hline VERITAS & Porto Alegre & v. 51 & n. 2 & Junho 2006 & p. 109-116 \\
\hline
\end{tabular}


em atentar ao horizonte privilegiado do eu transcendental ou puro, enquanto doador de sentido em relação ao eu empírico, mundano. Com a desconexão do mundo natural obtém-se uma nova região de eventos, ainda não vislumbrada e, muito menos, deslindada em seu caráter próprio: a intencionalidade da consciência. Esta caracterização do fluxo de consciência tem grande importância no desenvolvimento da fenomenologia husserliana, podendo-se considerá-la, numa aproximação preliminar, como a imbricação instauradora de cogito e cogitatum, no sentido de que não se pode falar de sujeito sem uma referência explícita ou implícita ao(s) objeto(s) por ele constituído(s).

É exatamente o estatuto de evidência do eu transcendental, critério último a que remetem todas as demais evidências, que constitui o fio condutor das análises husserlianas. Para averiguar-se de modo competente a solidez do ponto arquimediano estabelecido por Husserl, faz-se necessário vinculá-lo a temas conexos, essenciais para sua compreensão, entre os quais se destacam o tempo, a redução e a intersubjetividade. No texto Sobre a fenomenologia da consciência íntima do tempo e noutros escritos esparsos o autor procura mostrar como o transcorrer temporal, em seus aspectos de presença, retenção e protensão determinam essencialmente a configuração geral e as articulações intrínsecas da subjetividade transcendental. Do mesmo modo outros escritos, mormente o segundo volume de Filosofia primeira, procuram explicitar que a emergência do eu transcendental depende do radicalismo do processo de redução em seus diferentes níveis. Só há pureza egológica em concomitância ao grau mais elevado da colocação entre parênteses do mundo e da atitude natural que o sustenta. Por fim, deve-se destacar a quinta das Meditações cartesianas enquanto formulação mais sistemática da tentativa husserliana de resolver a grave acusação de solipsismo transcendental dirigida ao projeto fenomenológico em seu conjunto.

No âmbito do procedimento de redução, a fenomenologia husserliana encontra o eu transcendental ou puro. Tal eu não é à consciência nem sua matéria nem sua forma, constituindo antes uma integração de ambas enquanto perpétua apropriação dos vividos. Portanto, o eu transcendental não é um fato no sentido do eu empírico. Ele é, ao contrário, o fato do mundo, que ele constitui exatamente enquanto transcendental. A questão que se coloca é aquela concernente ao sentido da presença vivente do eu a si próprio. Husserl pensa tal sentido enquanto Urkonstitution. Esta experiência é aquela de uma síntese, a mais originária das sínteses, sob a qual se executam todas as outras. $\mathrm{O}$ que se encontra nesse nível é a forma originária da unidade do fluxo, ou seja, a consciência interna contínua do tempo. O eu puro é a experiência da unidade da vida universal da consciência, a qual precede todo estado de consciência individual. Isto significa que a vida existe para si própria, se apreende em seu próprio fluxo como identidade na qual o eu transcendental é o pólo articulador. Auto-apreensão problemática, pois mobiliza uma intencionalidade transversal que perpassa a consciência ao invés de a transcender.

Se a consciência recebe seu sentido egológico em sua auto-temporalização, o eu é, entretanto, sempre anterior a esta constituição primitiva do proto-tempo, ou seja, do tempo da presença vivente do eu a si próprio. O eu encontra-se sempre 
no fluxo, se o tomamos por um ente. Sendo assim, é necessário pensá-lo como o idêntico da proto-constituição temporal. Contudo, o eu não é apenas um ente, e como tal se encontra além do fluxo. O eu precede a produção universal de todos os entes, no sentido de que ele é seu pressuposto estrutural. Podemos nos ater ao fluxo em si e dirigir a visada fenomenológica sobre a constituição de uma identidade primeira no e pelo fluxo, aquela do eu de que descobrimos após que o fluxo a pressupõe. Se Husserl fecha este círculo e atribui um privilégio ao eu é por que a visada fenomenológica, onde se instaura o fenomenal, que num sentido não equivale ao eu, é intrinsecamente comprometida com a efetividade. O fluir pode ser compreendido por si mesmo, mas enquanto sua compreensão é possível, ela problematiza a possibilidade de toda possibilidade. Esta possibilidade primordial ocorre na efetividade do fenomenólogo. A temporalização formal não é passível de enquadramento fenomenológico senão a partir da temporalização efetiva e esta não é a do fluxo, mas a do eu puro em sua operação contínua de constituição.

Isso coloca algumas questões importantes: como o eu articula a temporalização efetiva, enquanto ele se constitui à medida mesmo em que ela se efetua? Como esta operação do hilético (efetivo) pelo eu transcendental funciona? A alternativa husserliana de solução passa pela abordagem fenomenológica da afecção, ou seja, do encontro pelo eu de um nó que lhe é estranho, estritamente contemporâneo a ele e que o instaura na modalidade de eu. A hylé é o componente que permite pensar-se a ligação do eu a si próprio, que implica a estrutura egológica como contínua recentração. Ela cria a polarização característica do eu, na medida em que é alteração, emergência do outro no eu, que lhe permite se constituir para si.

Cabe indagar: donde provém o poder afetante da hylé? Da imbricação nela dos dados sensuais e do sentimento que o eu prova numa só experiência nativa de si. A hylé afeta por que é essencialmente afetiva. Afetividade primordial da hylé que condiciona uma perpétua receptividade. A hylé atrai o eu além de si mediante o sentimento. Ela produz um dirigir-se do eu a um horizonte de protensão. Há, portanto, uma primazia do futuro na instauração do tecido da consciência. Privilégio do futuro que implica numa nova concepção da transcendência. O presente se constitui numa intencionalidade de preenchimento, e esta procede do futuro ao presente. A contínua auto-transcendência do fluir reenvia a uma transcendência que não é aquela de um objeto, que não é o referente de nenhuma intencionalidade, mas que é aquela do dado em sua insuficiência de princípio que faz a constante abertura do campo da consciência.

Além dessas implicações temporais na constituição do eu transcendental enquanto espectador desinteressado que apenas descreve os vividos e seus componentes intencionais, o próprio processo de redução repercute diretamente na legitimidade daquela formação egológica pura. O problema que se apresenta de imediato concerne à elucidação do modo de ser inerente ao eu reduzido, a partir do qual se dá toda instauração de mundo. Como entender tal cisão egológica? Qual a diferença entre o eu empírico, mundano e o eu supérstite à redução? Sobretudo, quais as relações possíveis entre ambas as atividades egológicas? Indagações que alcançam o núcleo do programa fenomenológico husserliano. 
Para Husserl, o eu transcendental é produto de uma descoberta e de uma conquista. O eu puro se descobre ao suspender a tese posicional do mundo, no qual se inclui a existência permanente do eu empírico. Mas esse campo transcendental assim aberto deve ser conquistado gradativamente, numa tarefa infinita, porém determinável, de elucidação. A situação do fenomenólogo que vislumbra de modo transcendental o ego constituinte equivale àquela do cego de nascença que se submete deliberadamente a uma intervenção cirúrgica bem sucedida, cabendolhe doravante aprender a ver e a explorar de maneira sistemática o novo território perceptivo, tornando-o familiar e compreensível.

Todo filósofo autêntico deve pautar sua atividade por um radicalismo absoluto, no sentido de buscar um conhecimento que se funde e se justifique desde seu próprio âmbito de instauração. Com tal propósito, ele deve começar por uma crítica apodítica das evidências naturais que subsistem nas ciências positivas. Previamente a qualquer elaboração teórica, as ciências específicas dispõem de objetos que perfazem seus circuitos de atuação no âmbito da experiência natural. Tal postura ingênua compromete a fundação do conjunto da empreitada científica, pois ela não tematiza nem compreende a vida e a atividade transcendentais da consciência que experimenta e pensa todo aparecer mundano, e assim funda todo conhecimento legítimo. Portanto, a deficiência no fundamento das ciências específicas não pode ser superado mediante um mero aperfeiçoamento na eficácia de suas pesquisas intrínsecas, demandando antes uma mudança radical de método na abordagem dos objetos peculiares de suas áreas efetivas de exercício.

Suspensa a validade fundante das ciências positivas, a próxima démarche metódica refere-se à avaliação do estatuto fundante da experiência do mundo, com todos os eventos particulares que nele ocorrem. Não se trata de averiguar a pertinência das ilusões, dos enganos eventuais que acometem os diferentes modos de aparecimento. Trata-se antes de investigar o grau de evidência da existência do mundo, ou melhor, de aferir o alcance da proposição "o mundo é". Examinada radicalmente, a experiência do mundo mostra-se contingente, pois se o eu, enquanto sujeito da experiência, pode se convencer com clareza da não-existência do mundo que aparece, ainda que a título de exercício ficcional, então o conhecimento do mundo tomado como existente não constitui necessidade apodítica. Isto mostra o caráter apenas presuntivo de toda experiência externa, pois todo conhecimento apodítico exclui absolutamente toda possibilidade do não-ser ou do serde-outro-modo do objeto conhecido.

Abalada a confiança na existência do mundo, resta ainda perguntar pelo estatuto do eu que pretende conhecer o mundo. Deve-se aferir agora o alcance da proposição "eu sou". Embora o mundo possa não existir, eu, que experimento todo aparecer mundano com meu fluxo contínuo de vivências, percepções, lembranças, antecipações, eu existo? A partir dessa pergunta começa a esboçar-se uma duplicação do eu (Ichverdoppelung), ou melhor, uma dupla significação do eu. Dum lado, o euobjeto, composto de uma efetividade psicofísica subordinada aos encadeamentos causais e pertencente à totalidade mundana, sendo, portanto, submetido à mesma contingência que esta. Doutro lado, o eu-sujeito, constituído de modo transcenden- 
tal e funcionando como condição de possibilidade e de sentido para toda ocorrência objetiva. A assimilação entre os dois eus é completa, bastando executar a atitude natural para que se descubra o primeiro, e efetuar a atitude transcendental para que se vislumbre o segundo. O eu-sujeito não pode ser negado de nenhum modo, pois é justamente ele que opera toda a crítica do conhecimento, efetivo ou possível, tanto de minha efetividade psicofísica quanto do universo em geral. É inerente ao eusujeito ser o que é em sua ipseidade, mesmo que o eu-objeto e o mundo deixem de subsistir. Isto significa que o eu transcendental instaura a si desde uma dimensão pura, como mera visada constituinte.

Mediante a redução fenomenológica eu, enquanto ente psicofísico, posso a todo momento suspender meu ser-homem sem que por isso deixe de valer o fluxo de minha vida transcendental. A suspensão da validade do mundo implica apenas a suspensão da validade da apercepção que me objetiva como ser-no-mundo. O grande mérito do método de redução concerne justamente à constatação de que por trás dessa vida mundana eu disponho de uma vida absolutamente fechada sobre si e que desde si desenvolve uma ininterrupta operação objetivante, pois ela forma em si um mundo objetivo como seu fenômeno. O estatuto ontológico do mundo, quaisquer que sejam os seus modos, depende de minha atividade de constituição transcendental: ele aparece para mim, vale para mim, subsiste mediante minhas operações transcendentais, que o exibem e o confirmam a cada momento. Portanto, toda objetividade que se apresenta só pode legitimamente ser considerada como tal pela confirmação que meu ato transcendental lhe outorga.

O propósito central da fenomenologia husserliana consiste exatamente em elucidar paulatinamente a constituição transcendental do eu-sujeito. Um texto paradigmático na consecução dessa tarefa são as Meditações cartesianas. Na quarta meditação o eu-sujeito é caracterizado de três modos principais e complementares: pólo idêntico dos estados vividos, substrato dos habitus e universo das formas possíveis de experiência. O primeiro aspecto realça que o ego transcendental não se dilui nas multiplicidades particulares de suas cogitationes; ao contrário, ele se apresenta como supremo núcleo de identificação, não só de seus objetos efetivos ou possíveis, mas, sobretudo, de sua própria atividade constituinte. A visada transcendental engendra desde si a síntese necessária à conexão das vivências sob um sentido único reapropriado continuamente e manifestado pela atribuição sempre legítima da expressão "minhas vivências". O segundo aspecto destaca que a subjetividade pura se determina enquanto identidade dinamicamente plena, capaz de confirmar-se a cada acréscimo transcendental; com isso, todo ato do eu puro outorga-lhe uma propriedade estável correspondente, mesmo que a orientação semântica original do ato seja posteriormente abandonada. Tal persistência do ato forma o que Husserl denomina habitus, ou seja, a capacidade do eu de retornar continuamente a suas manifestações e de assumi-las integralmente enquanto suas, produtos de seu estilo de apropriação. É mediante o habitus que se instaura a permanência dos objetos efetivos ou possíveis inerentes ao ambiente mundano de cada eu concreto. O terceiro aspecto ressalta o a priori universal pertencente ao eu puro, com suas formas e tipos apriorísticos tanto de potenciali- 
dades quanto de atualidades do fluxo intencional. Só há experiência, ou seja, compossibilidade dos estados vividos porque o eu transcendental opera continuamente gêneses ativas e passivas em consonância a motivações transcendentais determinantes da infinidade de estruturas noético-noemáticas.

Conquistado o terreno da subjetividade transcendental, cabe ao fenomenólogo conscientizar-se de que este triunfo, embora importante, representa apenas um começo demandando explorações inesgotáveis. Sobretudo, cabe ao fenomenólogo defrontar-se com questões novas, entre as quais destaca-se aquela concernente ao solipsismo transcendental. A redução fenomenológica, tal como Husserl a expõe em vários textos, tem como ponto de chegada o eu puro daquele que a executa. Deste modo, uma fenomenologia transcendental só parece possível enquanto egologia transcendental. O fenomenólogo parece estar condenado à condição de pensador solipsista, sendo-lhe vedado o acesso à experiência transcendental de qualquer alter ego, ou, na terminologia husserliana, privando-o do fundamento da intropatia. Cabe indagar: qual o estatuto transcendental dos outros egos? Como realizar uma redução intersubjetiva?

Questões que convocam ao cumprimento de uma tarefa, à qual Husserl reconhece não haver correspondido ao longo de considerável parcela de suas reflexões e escritos: explicitar as motivações e sínteses mediante as quais se forma no eu puro o sentido do alter ego, ou seja, clarificar como se processa e se fundamenta a experiência transcendental em que o outro se apresenta. É, sobretudo, na quinta das Meditações cartesianas que Husserl pretende dar conta da tarefa. Ele se indaga: - de que modo a experiência do outro se manifesta na esfera primordial, ou seja, no âmbito do que me é dado enquanto minhas vivências? É evidente que o outro não se dá a mim de modo imediato, tal como me manifesto a mim na dimensão da atualidade. Tal incompletude da experiência do outro não seria eqüivalente àquela da experiência do eu próprio na modalidade do passado?

A compreensão do processo constitutivo do alter ego em minha experiência própria implica que se entenda que tal experiência própria pode dar-se sob a modalidade da reflexão atual ou como presentificação derivada do exercício mnemônico. Toda vez que o eu empírico se relaciona afetivamente com uma presença corporal estranha, ele tem diante de si uma existência num corpo subjetivo, que lhe demanda um comportamento somático. Na presença deste organismo, deste corpo animado eu tomo consciência de um sujeito com o mesmo grau de evidência que em minha própria presentificação mnemônica, embora seja a subjetividade do outro que ali se expõe. Isto significa que a consciência no eu do alter ego não deriva de mera inferência lógica. Não se trata na experiência do outro de um simples raciocínio por analogia fundado na vivência própria: o alter ego forma uma estrutura subjetiva original que se inclui legitimamente na subjetividade geral enquanto instauradora de todo e qualquer sentido.

Partindo da esfera do pertencimento (Eigenheits-sphäre), entendida como circuito transcendental e total da intencionalidade de meu ser próprio, descobre-se que a camada primordial de emergência do outro é a apresentação (Appräsentation), ou também denominada por Husserl de apercepção analógica. A apresentação constitui 
um tipo de associação ou, numa terminologia mais precisa, de emparelhamento (Paarung). O fenômeno objetivo de meu corpo próprio, que se comporta de variadas maneiras em situações também variadas, se emparelha ao fenômeno de outro ente humano qualquer subordinado a comportamentos diversos, mas consonantes. Ocorre assim, de maneira necessária, uma apreensão assimiladora, uma comunhão intencional. Desse modo, compreende-se que o outro constitui, no âmbito transcendental, uma modificação do eu, estabelecendo-se um regime pleno de coexistência.

O grau de evidência da apresentação do outro coloca em xeque o radicalismo da redução solipsista, demandando uma redução intersubjetiva. A conquista da subjetividade transcendental outorga a primazia à primeira pessoa. Entretanto, a experiência do alter ego encaminha à ampliação do circuito desta primazia à segunda e à terceira pessoas, numa pluralidade de mônadas que operam suas sínteses constitutivas em regime de interação mútua. Instaura-se assim uma comunidade monadológica, no seio da qual se dá a experiência transcendental de um mesmo mundo. Toda objetividade para mim vale do mesmo modo para qualquer outro, e desfruta de existência transcendental enquanto unidade de conhecimento constitutivo que se forma a título de correlato intencional na vida cognitiva de qualquer ego, tudo isto sem que eu saia de minha esfera de pertencimento. O mundo se constitui na minha esfera primordial enquanto unidade idêntica de meus múltiplos modos de representação e de apresentação. Todas essas estruturas me são mostradas na modalidade do pertencimento, acessível mediante a explicitação de meus vínculos transcendentais. Na apresentação do alter ego operam as mesmas estruturas sintetizantes, permitindo estendê-las à constituição de todos os conteúdos noemáticos a ele inerentes e assim legitimar o estatuto transcendental do mundo comum. Ocorre o mesmo com as objetividades ideais, tais como a série dos números ou as teorias científicas, sejam elas constituídas em minha esfera transcendental ou naquela do outro.

Várias críticas foram dirigidas ao conceito husserliano de intersubjetividade, destacando-se aquelas formuladas por Alfred Schütz: - Como determinar o alter ego na experiência original para que se possa atingir, mediante a segunda redução, o domínio do pertencimento próprio? - Como distinguir, na experiência original, o alter ego enquanto objeto e enquanto co-sujeito da experiência, que co-determina o sentido de toda objetividade? Qual sentido pode ter o comportamento do outro como objeto de experiência interiormente coerente, de acordo com si mesmo e podendo ser legitimado neste acordo? - A comunicação transcendental das subjetividades repousa sobre a comunidade do mundo ou, ao contrário, o mundo comum é que se funda sobre a experiência da comunicação universal?

Eis uma amostra da originalidade, mas também dos impasses inerentes à concepção husserliana de subjetividade transcendental, sendo que para explorá-la em todas as suas minúcias deve-se acompanhar criticamente o pensamento husserliano desde sua emergência até seus últimos esboços, não com um intuito meramente filológico ou de caráter histórico, mas para poder, a partir do conjunto das reflexões do pensador alemão, encontrar alternativas à controvérsia concernente ao estatuto do sujeito, um dos eixos em torno aos quais gravita o destino da filosofia contemporânea, em todos os seus aspectos e tendências. 


\section{Referências}

BERGER, Gaston. Le cogito dans la philosophie de Husserl. Paris: 1941. Aubier.

BERNET, R. La vie du sujet. Recherches sur l'interpretation de Husserl dans la Phénoménologie. Paris: 1994. PUF.

DERRIDA, Jacques. La voix et le phénomène. Paris: 1967. PUF.

FINK, Eugen. De la phénoménologie. Paris: 1974. Minuit. Traduzido do alemão por Didier Franck.

FRANCK, Didier. Chair et corps - sur la phénoménologie de Husserl. Paris: 1981. Minuit.

HEIDEGGER, Martin. Les problèmes fondamentaux de la phénoménologie. Paris: 1985. Gallimard. Traduzido do alemão por Jean-François Courtine.

HUSSERL, Edmund. Husserliana - Gesammelte Werke. Auf Grund des Nachlasses veröffentlicht vom Husserl-Archiv (Leuven) unter Leitung von H. L. van Breda und S. Ijsseling, Den Haag, Martinus Nijhoff, 1950 segs. (Volumes I a XIX e XXI a XXIX).

LANDGREBE, Ludwig. Phänomenologie und Metaphysik. Hamburgo: 1949. Felix Meiner.

LAUER, Quentin. Phenomenology - Its genesis and prospect. New York: 1965. Harper \& Row.

LÉVINAS, Emmanuel. En découvrant l'existence avec Husserl et Heidegger. Paris; 1988. Vrin. , Théorie de l'intuition dans la phénoménologie de Husserl. Paris: 1984. Vrin.

LYOTARD, Jean-François. La Phénoménologie. Paris: 1954. PUF.

MARION, J. L. Étant donné. Essai d’une Phénoménologie de la donation, Paris: 1997. PUF.

MOURA, Carlos A. R. Crítica da razão na fenomenologia. São Paulo: 1989. Nova Stella.

MURALT, A. L'Idée de la Phénoménologie - L’exemplarisme Husserlien, Paris: 1958, PUF.

NABAIS, Nuno, A evidência da possibilidade - A questão modal na fenomenologia de Husserl. Lisboa: 1998. Relógio D’Água.

SCHUTZ, A. "Le problème de l'intersubjectivité transcendantale chez Husserl", in Husserl, Cahiers de Royaumont - Philosophie Nr. III, Paris, Editions de Minuit, 1959, pp. 334-365.

SOKOLOWSKI, Robert. Husserlian Meditations - How words present things. Evanston: 1974. Northwestern University Press.

SPIEGELBERG, H. The phenomenological movement. Haag: 1971. M. Nijhoff.

TUGENDHAT, Ernst. Der wahrheitsbegriff bei Husserl und Heidegger. Berlim: 1967. De Gruyter.

WAELHENS, A. de. Phénoménologie et vérité. Paris: 1953. PUF. 